\title{
Comparison of Objectively Structured Viva Voce and Modified Objectively Structured Viva Voce as Assessment Tool during Formative and Summative Examination in Dentistry
}

\author{
Pradnya Nikhade ${ }^{1}$, Shweta Sedani², Nikhil Mankar³, Abhilasha Das ${ }^{4}$, Sindhu P5, Shruti Mishra ${ }^{6}$
}

1, 2, 3, 4, 5, 6 Department of Conservative Dentistry and Endodontics, Sharad Pawar Dental College, Datta Meghe Institute of Medical Institute, DMIMS (DU), Sawangi, Wardha, Maharashtra, India.

\section{ABSTRACT}

\section{BACKGROUND}

Assessment is an essential part of any curriculum, including that of dentistry. Assessment of knowledge is currently done through examination and thus examination is an inherent part. Examination and assessment of knowledge is done so as to promote the students to the next level. Currently, two types of methods are used for the assessment and performance of students, subjective and objective. Recently objective methods are preferred over 24 subjective methods. Student's performance can be accessed via relevant feedback. During summative examinations at the end of course, the assessment now has been supplemented by the formative ones. The skill assessment is subjective in nature as well as lacks possibility for direct assessment of the presentation of skills by the evaluator.

\section{METHODS}

50 students from I BDS class, were selected randomly. These students were subjected to conventional OSVV in the subject of dental anatomy and dental histology. The viva voce was taken using predesigned templates having 10 questions with various difficulty levels - easy, difficult and very difficult. The questions were from must know, desirable to know as well as nice to know areas. Same students were subjected to modified OSVV with prior consent and after IEC clearance was obtained. The scores were obtained from the students after viva voce with modified templates and modified difficulty levels. The study was done during second PCT as well as preliminary examinations. The scores were compared.

\section{RESULTS}

There were 5 students who scored high in modified OSVV pattern during formative (II PCT) and 6 students who scored high during summative (preliminary) examinations. There was no significant difference in the mean scores between the two methods.

\section{CONCLUSIONS}

Students who scored high marks when subjected to the modified OSVV were rapid learners and modified pattern of OSVV can be useful to improve the score of students.

\section{KEY WORDS}

Objectively Structured Viva Voce (OSVV), Modified Objectively Structured Viva Voce (Modified OSVV), Assessment
Corresponding Author: Dr. Pradnya Nikhade.

Department of Conservative Dentistry and Endodontics, Sharad Pawar Dental College, Datta Meghe Institute of Medical Institute, DMIMS (DU), Sawangi, Wardha, Maharashtra, India.

E-mail: smilinglady_pradnya@yahoo.co.in

DOI: $10.14260 /$ jemds/2020/654

How to Cite This Article:

Nikhade P, Sedani S, Mankar $N$, et al. Comparison of objectively structured viva voce and modified objectively structured viva voce as assessment tool during formative and summative examination in dentistry. J Evolution Med Dent Sci 2020;9(40):2987-2991, DOI: 10.14260/jemds/2020/654

Submission 13-05-2020,

Peer Review 28-08-2020,

Acceptance 04-09-2020,

Published 05-10-2020.

Copyright (C) 2020 Pradnya Nikhade, et al. This is an open access article distributed under Creative Commons Attribution License [Attribution 4.0 International (CC $B Y 4.0)]$ 


\section{BACKGROUND}

Conduction of examinations is done regularly during the whole year. This way the assessment of knowledge is done so as to promote the students to the next level. Recently objective methods are preferred over the subjective methods. Viva voce examination per se is focused on comprehension application of the basic knowledge and concepts and its implicit logical confirmation. It is precisely toward analysing, creating, and evaluating the real depth of knowledge in the higher levels of cognitive domain. ${ }^{1}$ Further, it does assess effectively the attitude, communication power, and convincing power of the affective domain. ${ }^{2}$ It has high face validity and assesses what cannot be assessed by a written examination.1,3 This is possible only when this tool is used thoughtfully, rationally, objectively and relevantly.

Performance of students and their perpetual learning can be very well assessed via relevant feedback. During summative examinations at the end of course, the assessment now has been supplemented by the formative ones. Conventional methods of viva may have variations in the:-

- Allotment of time for each student,

- Total number of questions asked

- The levels of difficulty of the questions asked

Entire syllabus may not be covered. ${ }^{4}$

Here appears to be a variation on what constitutes the "traditional" oral examination.1,2,5,6 Generally, the viva voce assessment matches with theory to a large extent with a good correlation. Since the viva voce specially assess the higher domains of cognition and affect, $, 1,2$ the scoring in viva voce is expected to be more difficult than theory and specifically be following the theory from a lower side but not on the higher side of it (again with a rider that theory is assessed as per the standard norms!).

It is commonly observed that traditional oral examinations are held usually toward the end of the practical examination when a student is tired of practicals. It is taken casually and marred by high subjectivity of the examiners. ${ }^{2,3,6,7}$ Examiners are confounded with their whims, fancies, and their way of understanding of the subject, their preferred content area, and by numerous other momentary environmental factors.5,6,7 Moreover, it is totally oriented toward theory while the examinee's concentration is mainly on practical's related theory.

The skill assessment is subjective in nature as well as lacks possibility for direct assessment of the presentation of skills by the evaluator. Hence to overcome these limitations, Objective structured Viva Voce has been described by Harden et al at the Dundee University in 1975, for assessment of clinical subjects. OSVV was found to be a reliable approach to assess the student in a more defined and impartial way. All the examinees are exposed to pre-validated questionnaire so as to avoid any discrimination. The standard structure of objective structured viva voce has been made effective by the typical question pattern from various levels of difficulty. This way the bias can be avoided but for the fast learners (rapid learners) the pattern of subjecting these students to the modified pattern of OSVV may increase their performance.

The primary fault in conventional oral examinations is unreliability. 6,8 Due to confounding situational factors, anxiety of the examinee, and inconsistency of the examiners that needs a revamping. ${ }^{9}$ To look for such a discrepancy in assessment and the way it is presently conducted, we analysed semester examination results and tried to make it a more viable, uniform, transparent, and effective tool of assessment by structured viva voce examination. The purpose of this study was to translate the modified OSVV tool into a robust method of assessment by which the student may be able to score more marks and his / her actual learning is assessed in the desired domains.

Thus, it can be postulated that the modified OSVV can be a better tool for the precise assessment of learners from the batch of first BDS dental students.

As per the concept of conventional OSVV, the weightage of Viva-Voce is divided in the categories as -

- Must know - $60 \%$

- Desired to know - $30 \%$ and

- $\quad$ Nice to know - $10 \%$

- Complete syllabus is considered as $100 \%$

In order to test the competency of students, the conventional OSVV was modified as under-

- The number of questions asked were from MK (Must Know), DK (Desired to Know) and NK (Nice to know) levels. Very difficult question was shifted from MK to NK level.

- The same students were asked the very difficult question from NK area from the predecided theme.

Hence the goal of this maiden study was to modify the existing conventional objectively structured viva-voce and subject the students to the modified pattern. This study was planned to find out whether the modified OSVV can be a better tool for the assessment of rapid learners from the batch of first BDS dental students.

\section{METHODS}

After obtaining the informed consent from the concerned faculty and dental education unit of the university, the students were subjected to the conventional as well as modified version of OSVV at the formative and summative examinations. IEC clearance [Ref No. DMIMS (DU) / IEC / 2018 - 19 / 7535] dated 15.10.2018 was obtained for this evaluation from university cell.

This was randomized, double blind comparative evaluation study. Sample size was calculated using Open epi version 3 , open source calculator using the values from pilot study done to understand the feasibility of the study among 25 students who were not included in this study. The sample size was calculated to be 50 . The Viva questions are asked themewise and corresponding to the \% of marks attributed to the theme as per syllabus. A total of 10 questions are asked to the learner which covers the entire syllabus. Assessment of the learner is done depending on the number of answers received. Templates are to be prepared with 10 questions each where questions are from various levels of difficulty. Out of the 10 questions, 6 from must know, 3 from desired to know and one from nice to know are asked by the examiners according to themes. 


\section{Sharad Pawar Dental College and Hospital, DMIMS (DU) Sawangi Meghe, Wardha, Maharashtra}

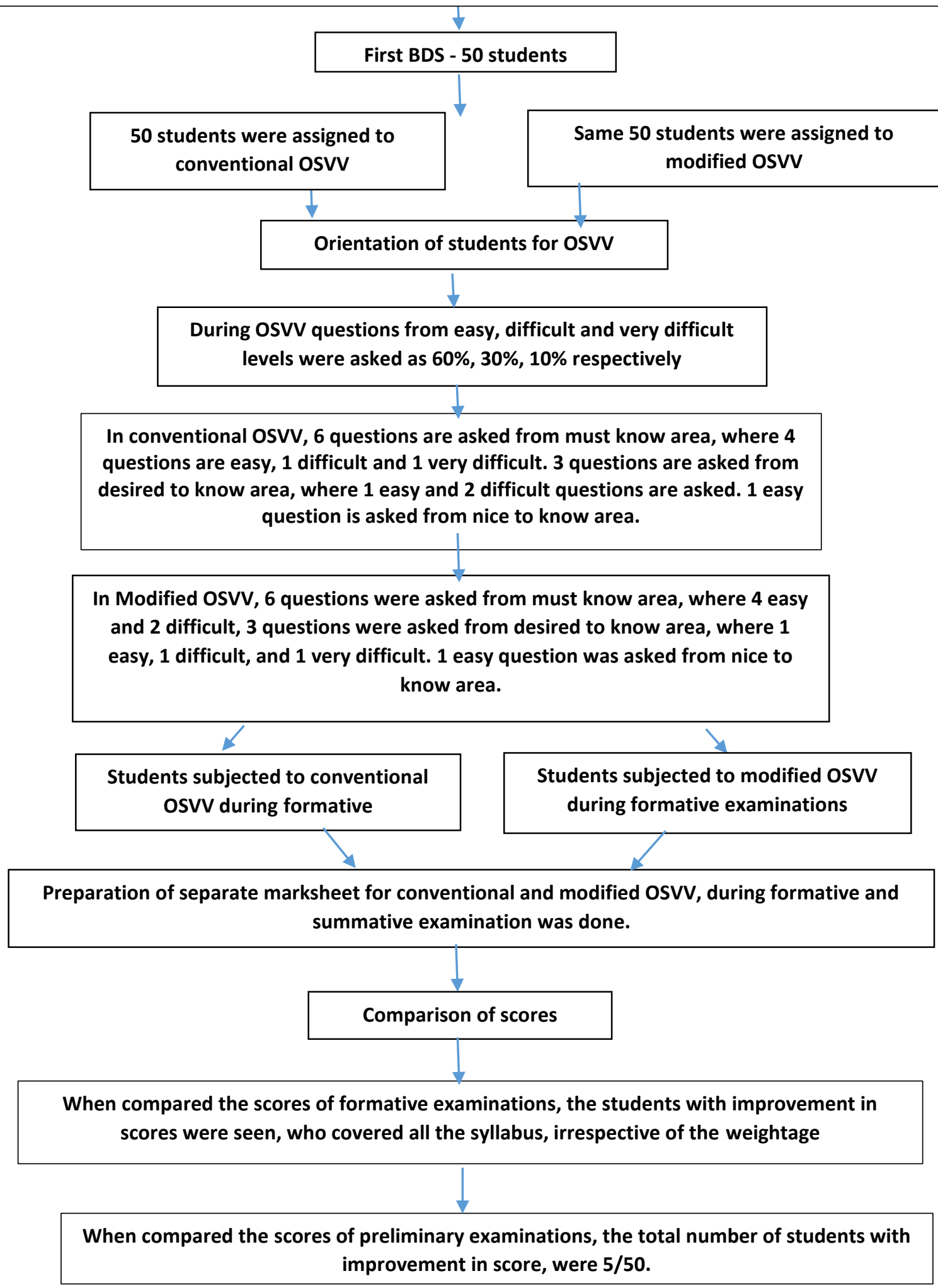

Fifty students were randomly selected by computer generated random numbers from BDS first year for modified objectively structured viva voce study. $\mathrm{N}=50$. The viva voce was conducted for the first BDS students in the subject of DADH.
These students were subjected to conventional OSVV, where the following method of conduction of Viva-Voce was used- 


\begin{tabular}{|ccc|}
\hline Level of Difficulty & Objective & Percentage \\
Easy & To test recall & 60 \\
Difficult & To test depth of knowledge & 30 \\
\hline Very Difficult & $\begin{array}{c}\text { Application of } \\
\text { knowledge }\end{array}$ & 10 \\
\hline
\end{tabular}

Same students were subjected to Modified OSVV, where the method of conduction of Viva-Voce was as follows- These students were asked the very difficult question from NK area. They were allotted more marks if they were able to answer very difficult question. The total number of marks were kept to 20 .

\begin{tabular}{|c|c|c|c|c|c|c|c|c|c|c|}
\hline & $\begin{array}{l}\text { Must } \\
\text { Know }\end{array}$ & & & & & & $\begin{array}{c}\text { Desired to } \\
\text { Know }\end{array}$ & & & $\begin{array}{l}\text { Nice to } \\
\text { Know }\end{array}$ \\
\hline 10 & 1 & 2 & 3 & 4 & 5 & 6 & 7 & 8 & 9 & 10 \\
\hline $\begin{array}{c}\text { Theme } 1 \text { - } \\
6\end{array}$ & E & E & $\mathrm{E}$ & E & $\mathrm{D}$ & VD & & & & \\
\hline $\begin{array}{c}\text { Theme } 2 \text { - } \\
3\end{array}$ & & & & & & & E & $\mathrm{D}$ & $\mathrm{D}$ & \\
\hline Theme & & & & & & & & & & E \\
\hline \multicolumn{11}{|c|}{ Mark Sheet for Conventional OSVV } \\
\hline$=2 \mathrm{Mark}$ & $\mathrm{D}=2 \mathrm{M}$ & & & & & & & & & \\
\hline
\end{tabular}

\begin{tabular}{|c|c|c|c|c|c|c|c|c|c|c|}
\hline & $\begin{array}{l}\text { Must } \\
\text { Know }\end{array}$ & & & & & & $\begin{array}{c}\text { Desired to } \\
\text { Know }\end{array}$ & & & $\begin{array}{l}\text { Nice to } \\
\text { Know }\end{array}$ \\
\hline & 1 & 2 & 3 & 4 & 5 & 6 & 7 & 8 & 9 & 10 \\
\hline 1 & E & E & E & E & E & D & & & & \\
\hline 2 & & & & & & & E & D & D & \\
\hline 3 & & & & & & & & & & VD \\
\hline \multicolumn{11}{|c|}{ Mark Sheet of Modified OSVV } \\
\hline
\end{tabular}

Themes depict the level of difficulty of questions asked as easy (E), difficult (D) and very difficult (VD). In conventional OSVV the template prepared would include 10 questions serially as depicted in the first table. At the end of examinations, the mark sheet and the score card was obtained for the formative (second PCT) and summative (preliminary or third PCT) examination.

\section{Statistical Analysis}

Once all the assessors agreed on the content, marking, and difficulty levels of the question, template was developed. The key to answers was also made and agreed by all examiners. Care was taken to make these templates equitable in all aspects so that any card could achieve similar assessment of a student. The viva voce marks were calculated, and then the scoring of the two tools was calculated for each student.

The scores were totaled for each student and mean, and standard deviation was calculated for both conventional OSVV and modified OSVV. The mean scores were compared using Wilcoxon signed-rank test. To compare the conventional OSVV and modified OSVV, the scores (marks) were subjected to a student's t test.

\section{RESULTS}

There were 98 students who appeared in formative (dental anatomy and dental histology) examination in all. All the students appeared for the examinations. Of the 98 students, 50 students were randomly selected from their results of theory and viva voce were analyzed.

When compared the scores of second PCT the total number of examinees with enhancement in score were 6 out of 50 . When compared the scores of preliminary examinations the total number of examinees with enhancement in score were 5 out of 50 .

\begin{tabular}{|ccccc|}
\hline Exam & Groups & Mean & $\begin{array}{c}\text { Std. } \\
\text { Deviation }\end{array}$ & P Value \\
$\begin{array}{c}\text { Part } \\
\text { Completion } \\
\text { Test (PCT) } \\
\text { 2nd }\end{array}$ & Conventional OSVV & 14.48 & 2.41 & 0.578 \\
\hline \multicolumn{4}{|c|}{ Table 1. Comparison of 2nd PCT Scores between } \\
\\
Conventional OSVV and Modified OSVV Groups \\
\hline
\end{tabular}

Table 1 depicts the comparison of scores obtained by the students when subjected to first conventional method of OSVV and later on subjected to modified OSVV. The difference in scores obtained by the learner was significant for 5 out of 50 students

\begin{tabular}{|c|c|c|c|c|}
\hline Exam & Groups & Mean & $\begin{array}{c}\text { Std. } \\
\text { Deviation }\end{array}$ & P Value \\
\hline \multirow{2}{*}{ Prelims } & Conventional OSVV & 13.88 & 2.82 & \multirow{2}{*}{0.490} \\
\hline & Modified OSVV & 14.14 & 2.95 & \\
\hline \multicolumn{5}{|c|}{$\begin{array}{l}\text { Table 2. Comparison of Prelims Exam Scores between } \\
\text { Conventional OSVV and Modified OSVV Groups }\end{array}$} \\
\hline
\end{tabular}

Table 2 depicts the comparison of scores obtained by the students when subjected to first conventional method of OSVV and later on subjected to modified OSVV. The difference in scores obtained by the learner was significant for 6 out of 50 students.

Out of 50 students, 5 students scored more marks compared to conventional OSVV in formative examination. 6 students scored more marks compared to conventional OSVV in summative examination. The comparison of scores of all 50 students in formative examination shows mean values as 14.48 and 14.68 . The standard deviation as 2.41 and 2.63. The p-value as 0.578 was not significant. The comparison of scores of all 50 students in summative examination shows mean values as 13.88 and 14.14 . The standard deviation as 2.82 and 2.95. The p-value as 0.490 was not significant.

There was no significant difference in the mean scores between the two methods. As no study has been carried out as modified OSVV, the observations from this study could not be compared with other studies. Hence these scores can be utilized as deciding point for those who could answer the very difficult question from nice to know area can be identified as rapid learners at the level of I

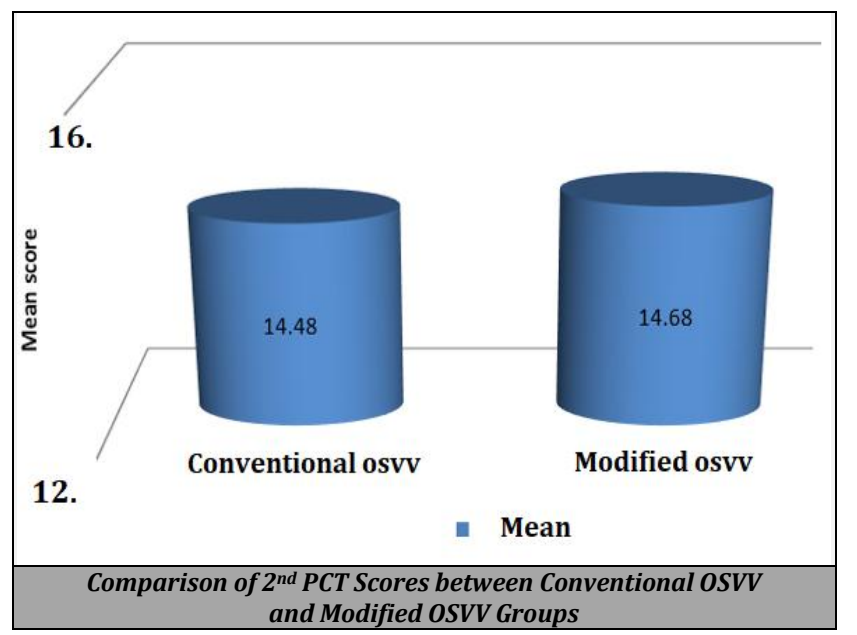




\section{DISCUSSION}

There appears to be a variation in scoring in conventional oral examination that is subjected to student, subject topics, teacher, and situational bias of oral viva voce examination as reported earlier.,2,6 Objectively structured Viva Voce is an established idea being used for evaluation of students as more reliable and objective approach. This way a logistic examination of large number of examinees completely and reasonably with least of stress is possible. ${ }^{10}$

According to the study carried out by Sule P. et. al 2017, same number of students were subjected to the traditional as well as OSVV, the marks obtained were subjected to statistical analysis and it was concluded that there was significant co relation between marks obtained by the students in the two formats of Viva Voce. ${ }^{8}$ OSVV was modified in such a way that, the minimum score of the student was at least $50 \%$. Very few studies have been reported in India that addressed the problems of viva voce examination in medical course prospectively 4 and retrospectively. Viva voce is a good evaluation technique. It can test all levels of knowledge (cognitive, psychomotor, affective domains), subtle skills, proper attitude and professional competence of a person. ${ }^{10}$

The methodology used in our study was somewhat similar to the conventional OSVV used elsewhere 4 . Our results of modified OSVV scoring was more exaggerated than conventional OSVV for selective number of the students which are in the group of rapid learners as observed earlier.1,7 Hardly, any student in modified OSVV group got less score in viva when compared to conventional group. The difficult question was shifted to DK area and the very difficult to NK area. It is observed that the NK area of syllabus is generally not read by the students. Only few students have the knowledge of NK areas of syllabus. Hence the students who could answer the very difficult question and difficult question from NK and DK areas of syllabus respectively scored more marks than when subjected to modified OSVV. When the students were subjected to conventional as well as modified OSVV,

Out of 50 students, 5 students scored more marks compared to conventional OSVV in formative examination. 6 students scored more marks compared to conventional OSVV in summative examination. The comparison of scores of all 50 students in formative examination shows mean values as 14.48 and 14.68. The standard deviation as 2.41 and 2.63. The p-value as 0.578 was not significant. The comparison of scores of all 50 students in summative examination shows mean values as 13.88 and 14.14. The standard deviation as 2.82 and 2.95. The p-value as 0.490 was not significant.

There was no significant difference in the mean scores between the two methods

- As no study has been carried out as modified OSVV, the observations from this study could not be compared.

- Hence these scores can be utilized as deciding point, as those who could answer the very difficult question from nice to know area can be identified as rapid learners at the level of I BDS.

There could be multiple advantages of using structured viva voce as wide coverage of syllabus, better expression of the learner, disinhibition, reduced anxiety, and shyness of the students in contrast to traditional viva voce that is marred with high subjectivity, lack of a format and uniformity, and unreliability. ${ }^{6}$ It is known that performance in structured viva has a direct relationship with performance that can be enhanced to a large extent by modified OSVV. With this pattern, rapid learner's performance will also improve. Student gets multiple chances. Student-teacher and studenttopic bias are not there. Hence it will help rapid learners to score more.

No previous assessment of learners has been carried out using modified OSVV hence this study can be referred as maiden venture in the faculty of dentistry.

\section{CONCLUSIONS}

Modified OSVV may be better than conventional OSVV for a group of students who routinely score high. Students perception of modified OSVV was positive and was up to their utmost satisfaction. A more thoughtful modification is the need of the hour for enhancing the score of rapid learners. This pilot study may be further carried out on a larger scale adding multiple parameters as there is immense scope for improvement in viva voce examination.

Financial or Other Competing Interests: None.

\section{REFERENCES}

[1] Torke S, Abraham RR, Ramnarayan K, et al. The impact of viva-voce examination on students performance in theory component of the final summative examination in physiology. J Physiol Pathophysiol 2010;1(1):10-2.

[2] Ray MK, Ray S, Ray U. Technology enabled assessment of viva voce: a new challenge. J Adv Res Biol Sci 2013;5:23842.

[3] Verma A, Mahajan N, Patel J, et al. Evaluation and comparison of results: conventional viva vs structured viva. Glob Res Anal 2013;2:188-90.

[4] Shaikh ST. Objective structured viva examination versus traditional viva examination in evaluation of medical students. Anat Physiol 2015;5:3.

[5] Singel TC, Shah C, Dixit D. Small group structured oral examination: an innovation in oral examination. NJIRM 2014;5(1):141-5.

[6] Davis MH, Karunathilake I. The place of the oral examination in today's assessment systems. Med Teach 2005;27(4):294-7.

[7] Haque $M$, Yousuf $R$, Baker SA, et al. Assessment in undergraduate medical education: Bangladesh perspectives. Bangladesh J Med Sci 2013;12(4):357-63.

[8] Sule PA, Ubale MR, Kartikeyan S, et al. Comparative study of objectively structured versus traditional viva-voce in microbiology amongst second-year MBBS students. IOSR Journal of Research \& Method in Education (IOSR-JRME) 2017;7(3):15-18.

[9] Harden RM, Stevenson M, Downie WW, et al. Assessment of clinical competence using objective structured examination. Br Med J 1975;1(5955):447-51.

[10] Bhadre R, Sathe A, Bhalkar M, et al. Comparison of objective structured viva voce with traditional viva voce. Int J Healthc Biomed Res 2016;5:62-7. 